\title{
Allozyme variation, linkage disequilibrium and diploid male production in a primitively social bee Augochlorella striata (Hymenoptera; Halictidae)
}

\author{
Laurence Packer* and \\ Robin E. Owen
}

\author{
Department of Biological Sciences, \\ University of Calgary, 2500 University Drive NW, \\ Calgary, Alberta, T2N 1N4, Canada.
}

\begin{abstract}
A population of the primitively eusocial bee Augochlorella striata was surveyed for allozyme variation at 47 loci for 35 enzyme systems with a mean number of haploid genomes sampled of 76 per locus. The expected heterozygosity (mean \pm S.E.) was $0 \cdot 107 \pm 0 \cdot 004$, the highest found for any bee species, solitary or social, studied to date. This result indicates that low levels of genetic variation are not ubiquitous in bees. No differences in allele frequencies between males and females were found. One diploid male was detected providing a maximum likelihood estimate of the frequency of diploid males in the population of $\mathbf{2 . 6}$ per cent. Strong linkage disequilibrium was detected between the loci Dia-2 and Lap. Under a genetic drift explanation for disequilibrium and realistic assumptions for the recombination rate between the two loci, the predicted population size is in broad agreement with that suggested from field studies.
\end{abstract}

\section{INTRODUCTION}

Hymenoptera generally have low levels of genetic variation (Metcalf et al., 1975; Pamilo et al., 1978). The reasons for this have been debated. One suggestion has been that mildly deleterious alleles are flushed out of hymenopteran populations because they are always expressed in the hemizygous males (Suomalainen, 1962; Crozier, 1970). Alternative explanations include the reduced effective population size caused by haplodiploidy (Pamilo and Crozier, 1981), the greater difficulty in obtaining balanced polymorphisms in haplodiploid (or sexlinked) systems (Haldane, 1926; Mandel, 1959) and the nest environment in social insects promoting homeostatic control leading to decreased heterozygosity (Selander and Kaufman, 1973; Snyder, 1974). Berkelhamer (1983) suggested that primitively social Hymenoptera have significantly lower levels of genetic variation in comparison to solitary or advanced eusocial hymenopteran species. It was suggested that this was caused by inbreeding which would also result in elevation in relatedness between nestmates thereby favouring the evolution of sociality according to the kin

\footnotetext{
* Present address: Department of Biology, York University, 4700 Keele St., Downsview, Ontario, Canada, M3J 1 P3.
}

selection hypothesis (Hamilton, 1964; Wade and Breden, 1981). However, the difference that Berkelhamer claimed to have found disappeared when the species were correctly classified as to social level (Graur, 1985; Owen, 1985). Nonetheless, the situation remains unclear because so few primitively eusocial species have been adequately investigated for enzyme variation (Graur, 1985; Owen, 1985). Nonetheless, there is some indication that bees have particularly low heterozygosities even in comparison to other Hymenoptera (Owen, 1985). Clearly, more estimates of heterozygosity for Hymenoptera with different degrees of social organisation are required.

This paper provides information on genetic polymorphism in a population of the bee Augochlorella striata. This population is of particular interest because of its extremely low level of sociality (Packer et al., 1989a; Packer, submitted). A. striata is a member of the bee family Halictidae, a group well known for its wide range of social organisation and multiple origins of eusociality (Michener, 1974). In the population under consideration, only one half of the surviving nests became eusocial with colony sizes of two or three individuals-one queen (the original nest foundress) and one or two workers. The remaining nest initiating females were completely solitary: their 
daughters, upon reaching adulthood, mated and then excavated overwintering burrows. Thus, in some ways this population exhibited a very low degree of eusociality. However, unusually for a primitively eusocial halictine, workers' ovaries were completely undeveloped. For more details see Packer et al. (1989a) and Packer (submitted).

In addition to the basic genetic variation data, we present information on diploid male production and results indicative of strong $(D=0.073$, $P<0.01$ ) linkage disequilibrium between two (out of 21 pairwise comparisons) of the polymorphic loci. The latter is the first report of linkage disequilibrium within a haplodiploid genetic system.

\section{METHODS}

\section{Collection of samples}

The study site was at Irish Cove, Richmond County, Cape Breton Island, Nova Scotia (see Packer et al., 1989b, for a detailed description of the study site and nesting biology of the population). Bees used for electrophoresis were captured at the nest site late in summer 1987, after foraging activity had ceased; at various times during the spring and summer of 1988; or from nest excavations during 1987. All excavated bees had their head widths measured to the nearest $0.05 \mathrm{~mm}$. Bees were killed by freezing at $-80^{\circ} \mathrm{C}$ where they were stored until used for electrophoresis.

A total of 227 bees were used in the analyses, 109 caught at flowers and 118 excavated from 68 nests. From one to six individuals were used per nest with a mean $( \pm$ S.D.) of $1 \cdot 7 \pm 1 \cdot 05$.

\section{Electrophoretic techniques}

Bees were homogenised in 50 to $75 \mu$ l of cold distilled water using a nylon rod and a $1.5 \mathrm{ml}$ plastic eppendorf tube. Horizontal starch gel electrophoresis was carried out using 9.5 per cent starch gels (Connaught hydrolysed potato starch). The gel and electrode buffers used are shown in table 1. Homogenate was absorbed onto filter paper wicks (approximately $4 \times 12 \mathrm{~mm}$, Whatman number 1 or 3 ). All gels were run for between five and six hours at approximately $4^{\circ} \mathrm{C}$. Stain recipes generally followed those outlined by Packer and Owen (1989). However, alanine aminotransferase (=Glutamate oxaloacetate transaminase), cytosol aminopeptidase (=leucine aminopeptidase), guanylate kinase and L-iditol dehydrogenase (=sorbitol dehydrogenase), were not treated in the previous paper and the stain recipes used were from Cardy et al. (1980), Brewer (1970), Harris and Hopkinson (1976) and Shaw and Prasad (1970) respectively.

Enzymes that were found to be polymorphic early in the study were stained for as many individuals as possible. However, several variable systems have rather small sample sizes because the methods used to stain them were not developed until near the end of the investigation. Interpretation of banding patterns followed Packer and Owen (1989) with the following additional comments. (i) Acid phosphatase showed detectable variation only when run on bV gels: individuals run on bI are not included in the results. (ii) TPI and PGM exhibited prominent sub-banding in older females that mimicked genetic variation. Closer inspection revealed these enzyme loci to be monomorphic. (iii) Upon overstaining, several stain recipes containing NADP showed an additional polymorphic locus when run on tris-citrate gels. This was caused by IDH-the mobilities, pattern of variation and allelic designations were found to be identical when the same individuals were assayed for IDH and the alternative overstained enzymes (such as ME and G6PDH). (iv) Bands for $H k-1$ were extremely close to those of $H k$-2. It was difficult to separate heterozygotes from homozygous slow females for the former locus, consequently, only haploid males were scored for $H k-1$. (v) In general, scoring of gels was comparatively easy because most individuals used were male and therefore haploid.

\section{RESULTS}

\section{Allozyme variation}

The number of loci per enzyme and the number of haploid genomes investigated per enzyme are shown in table 1. An average of 76 haploid genomes were stained for the 47 loci from 35 enzyme systems. Table 2 lists the polymorphic loci, the mobilities of the alleles and the expected and, where applicable, the observed heterozygosities. There were significant deficiencies of heterozygotes at two loci, one of them probably resulting from small sample sizes (Pep-PP-1). In the other instance $(P g d)$ the heterozygotes that were found showed markedly reduced staining intensity and three females could not be scored at all. If these additional 3 individuals were heterozygotes, as seems probable, then the heterozygote deficiency disappears $\left(\chi_{(1)}^{2}=1 \cdot 11, P>0 \cdot 1\right)$.

The expected average heterozygosity $( \pm$ S.E. $)$ for the entire sample was $0 \cdot 107 \pm 0.004$ and the 
Table 1 List of enzymes, buffer systems, staining recipes and running conditions used



* anodal (a) or cathodal (c).

$\dagger$ running conditions and reference for buffer recipes: b1 and bV Shaw and Prasad (1970), 60 V and 75 V respectively; RSL, Ridgway, Sherburne and Lewis (1970) 65 V; CAM, Clayton and Tretiak (1972); AyB, Ayala et al. (1972) 60 V. All gels were run for between five and six hours.

proportion of loci that were polymorphic (where the frequency of the rarest allele is greater than 0.01 ) was 0.28 . It is possible that the use of several bees from some of the nests may have introduced some bias into the above calculations which were repeated including only one individual from each nest. The resulting expected heterozygosity was practically identical to the above estimate $(0 \cdot 106 \pm$ $0.004)$. This population has the highest level of heterozygosity reported for any bee. A comparison of this figure with that for other published values for Hymenoptera (Metcalf et al., 1984; Graur, 1985; Kuenzi and Coppel, 1986; Kukuk and May, 1985; Woods and Guttman, 1987; Packer and Owen, 1989) indicates that $A$. striata has sig- nificantly higher genetic variation at enzyme encoding loci than other bee species (t-test comparison of one value with a sample (Sokal and Rohlf, 1981), $t=3.43, P<0.005, n=40$ ) but not in comparison to the Hymenoptera as a whole $(t=1 \cdot 52, P>0 \cdot 1)$.

Table 3 compares allele frequencies between the sexes. There are no significant differences in allele frequency between males and females for any of the polymorphic loci.

\section{Diploid males}

One diploid male was detected as a heterozygote at the Idh locus (sex can be ascertained easily in 
Table 2 Electromorph mobility and heterozygosity calculations for polymorphic loci

\begin{tabular}{|c|c|c|c|c|c|c|}
\hline Locus & Allele & Mobility & $H_{\exp }$ & $H_{\mathrm{obs}}$ & $\chi_{(1)}^{2}$ & $P$ \\
\hline \multirow[t]{2}{*}{$A c p-1$} & 1 & 76 & $0 \cdot 355$ & 一 & & \\
\hline & 2 & 100 & & & & \\
\hline \multirow[t]{2}{*}{$A c p-2$} & 1 & 89 & 0.405 & - & & \\
\hline & 2 & 100 & & & & \\
\hline \multirow[t]{2}{*}{ Lap } & 1 & 94 & 0.435 & $0 \cdot 400$ & $0 \cdot 165$ & $>0.5$ \\
\hline & 2 & 100 & & & & \\
\hline \multirow[t]{2}{*}{ Dia-2 } & 1 & 97 & 0.428 & $0 \cdot 389$ & 0.691 & $>0.1$ \\
\hline & 2 & 100 & & & & \\
\hline \multirow{3}{*}{ Est-1 } & 1 & 100 & 0.543 & - & & \\
\hline & 2 & 130 & & & & \\
\hline & 3 & 143 & & & & \\
\hline \multirow[t]{2}{*}{ Est-2 } & 1 & 88 & 0.358 & - & & \\
\hline & 2 & 100 & & & & \\
\hline \multirow[t]{2}{*}{ G6pd } & 1 & fast & $0 \cdot 330$ & $0 \cdot 261$ & 1.037 & $>0.1$ \\
\hline & 2 & slow & & & & \\
\hline \multirow[t]{2}{*}{$H k-1$} & 1 & 93 & 0.049 & - & & \\
\hline & 2 & 100 & & & & \\
\hline \multirow[t]{2}{*}{$I d h$} & 1 & 52 & $0 \cdot 345$ & 0.289 & $1 \cdot 020$ & $>0.1$ \\
\hline & 2 & 100 & & & & \\
\hline \multirow[t]{2}{*}{$M e$} & 1 & 100 & 0.043 & 0.000 & & \\
\hline & 2 & 103 & & & & \\
\hline \multirow[t]{2}{*}{ Pep-PP-1 } & 1 & fast & 0.459 & $0 \cdot 200$ & see text & \\
\hline & 2 & slow & & & & \\
\hline \multirow[t]{2}{*}{$P e p-P P-2$} & 1 & fast & $0 \cdot 245$ & 0.267 & & \\
\hline & 2 & slow & & & & \\
\hline \multirow[t]{3}{*}{$P g d$} & 1 & 100 & 0.584 & $0 \cdot 182$ & see text & \\
\hline & 2 & 115 & & & & \\
\hline & 3 & 140 & & & & \\
\hline \multirow[t]{3}{*}{$P k$} & 1 & fast & 0.532 & - & & \\
\hline & 2 & medium & & & & \\
\hline & 3 & slow & & & & \\
\hline
\end{tabular}

these bees because of differences in head and abdomen shape, antennal length and leg colouration etc.). Diploid males issue from fertilised eggs which are homozygous at one or more highly polymorphic sex determining loci. Diploid males should be larger than average males in $A$. striata because the ovipositing female is fertilising an egg that "should" produce a female and there is significant sexual dimorphism in size in this species. The diploid male was indeed, significantly larger

Table 3 Genotype frequencies for males and females for polymorphic loci

\begin{tabular}{|c|c|c|c|c|c|c|c|}
\hline \multirow[b]{3}{*}{ Locus } & \multicolumn{5}{|c|}{ Frequency of genotypes in } & \multirow{2}{*}{\multicolumn{2}{|c|}{$\begin{array}{l}\text { Difference in } \\
\text { gene frequencies } \\
\text { between sexes }\end{array}$}} \\
\hline & \multicolumn{2}{|c|}{ Males } & \multicolumn{3}{|c|}{ Females } & & \\
\hline & 1 & 2 & 11 & 12 & 22 & $\chi_{(1)}^{2}$ & $P$ \\
\hline$A c p-1$ & 9 & 30 & - & - & - & - & \\
\hline Acp-2 & 11 & 28 & - & - & - & & \\
\hline Lap & 30 & 66 & 5 & 14 & 16 & $0 \cdot 17$ & $>0.5$ \\
\hline Dia-2 & 25 & 55 & 3 & 7 & 8 & 0.26 & $>0.5$ \\
\hline Est-1 & 37 & 33 & - & - & - & - & \\
\hline Est-2 & 22 & 45 & - & - & - & - & \\
\hline G6pd & 13 & 34 & 2 & 12 & 32 & 1.98 & $>0.1$ \\
\hline$H k-1$ & 121 & 3 & - & - & - & - & \\
\hline$I d h$ & 25 & 80 & 1 & 11 & 26 & $1 \cdot 52$ & $>0.1$ \\
\hline$M e$ & 2 & 88 & 0 & 0 & 10 & - & \\
\hline$P e p-P P-1$ & 6 & 6 & 9 & 3 & 3 & 1.48 & $>0.1$ \\
\hline$P e p-P P-2$ & 3 & 9 & 0 & 4 & 11 & 0.84 & $>0.1$ \\
\hline Pgd & 8 & 13 & 5 & 2 & 4 & $0 \cdot 18$ & $>0.5$ \\
\hline$P k$ & 15 & 9 & - & - & - & & \\
\hline
\end{tabular}


than average (one-tailed t test comparison between a single individual and a sample, $t=1.952, P<$ $0 \cdot 03, n=454$ ).

The total data for males at $I d \mathrm{H}$ was:

$\begin{array}{lllll}\text { Phenotype } & \mathrm{F} & \mathrm{FS} & \mathrm{S} & \text { Total } \\ \text { Number } & 80 & 1 & 25 & 106 \\ \text { Symbol } & \mathrm{A}_{2} & \mathrm{~B}_{2} & \mathrm{C}_{2} & \mathrm{~T}_{2}\end{array}$

A maximum likelihood estimate of the proportion of diploid males in the population, $\phi$, can be estimated from these data. First, allele frequencies are estimated by direct gene counting, hence $\hat{p}=$ $\left(\mathrm{A}_{2}+\frac{1}{2} \mathrm{~B}_{2}\right) / \mathrm{T}_{2}$ and $\hat{q}=1-\hat{p}$. It is important to realise that these estimates are valid regardless of the proportion of diploid males in the population. Thus, on the assumption of Hardy-Weinberg equilibrium, the estimate is

$$
\hat{\phi}=\mathrm{B}_{2} / 2 \hat{p} \hat{q} \mathrm{~T}_{2} \text {. }
$$

with variance, derived from the likelihood equation,

$$
\mathrm{V}(\hat{\phi})=\hat{\phi}\left[1-2 \hat{p} \hat{q} \hat{\phi}-(1-4 \hat{p} \hat{q}) \hat{\phi}^{2}\right] / 2 \hat{p} \hat{q} \mathrm{~T}_{2} .
$$

Further justification of these formulae will be presented elsewhere (Owen and Packer, in preparation). Hence, the proportion of diploid males in the population, $\hat{\phi}=0 \cdot 0258 \pm 0.0256$ (S.E.).

\section{Linkage disequilibrium}

The presence or absence of linkage or gametic frequency disequilibrium can be assessed directly at sex-linked or haplodiploid loci from the male haplotype frequencies.

Multilocus genotypes were recorded for 21 pairs of loci. All possible pairwise combinations of Acp-1, Acp-2, Dia-2, Est-1, Est-2, Idh, and Lap were compared, with a mean sample size (number of haplotypes) of $44 \cdot 24 \pm 10 \cdot 34$ (S.E.) For 20 of these comparisons there was no significant linkage disequilibrium $(\hat{D}<0 \cdot 0001)$. However, significant disequilibrium was observed between Dia-2 and Lap (table 4). The coefficient of linkage disequilibrium and its standard error were estimated using the formulae of Hill (1974) to give $\hat{D}=$ $0.073 \pm 0.026$, with corresponding correlation coefficient $r=0 \cdot 35$. This represents a considerable degree of disequilibrium as $D^{\prime}\left(\hat{D} / D_{\max }\right)=0 \cdot 40$, meaning that for these gene frequencies the observed disequilibrium is 40 per cent of its maximum possible value.

At sex-linked loci, $D$ can be different in males and females (Owen, 1988). Unfortunately, too few (16) two locus genotypes for females were available to provide a meaningful estimate of $D$.
Table 4 Observed and expected numbers of male haplotypes at Dia-2 and Lap

\begin{tabular}{lllll}
\hline \multicolumn{2}{l}{ Male haplotype } & & \multicolumn{2}{l}{ Number* } \\
\cline { 1 - 1 } Dia-2 & Lap & & Observed & Expected \\
\hline $\mathrm{f}$ & $\mathrm{f}$ & 36 & $31 \cdot 397$ \\
$\mathrm{f}$ & $\mathrm{S}$ & 10 & $14 \cdot 603$ \\
$\mathrm{~s}$ & $\mathrm{f}$ & 7 & $11 \cdot 603$ \\
$\mathrm{~s}$ & $\mathrm{~s}$ & 10 & $5 \cdot 397$ \\
Totals & & 63 & $63 \cdot 000$ \\
\hline
\end{tabular}

* Observed and expected numbers compared as a $2 \times 2$ contingency table using Cochran's continuity correction (Zar, 1984). The $\chi_{(1)}^{2}=7 \cdot 53$, is highly significant, $P<0.01$.

\section{DISCUSSION}

Hymenoptera appear to have lower levels of genetic variation than most other insect groups. However, there is considerable variation both within and between insect orders in this regard and this has made it difficult to provide a strong argument for haplodiploidy per se being the cause of low heterozygosities in Hymenoptera (Graur, 1985). The more advanced eusocial hymenopteran species may have particularly low levels of genetic variation (average mean expected heterozygosity across 14 species $=0.028$, S.E. $=0.005$ ) in comparison to primitively eusocial and solitary species which have an average heterozygosity of $0.048 \pm$ $0 \cdot 010, n=11$ and $0 \cdot 058 \pm 0 \cdot 008, n=34$ respectively (Graur, 1985; Kuenzi and Coppel, 1986; Kukuk and May, 1985; Metcalf et al., 1984; Woods and Guttman, 1987; Packer and Owen, 1989). However, because the majority of advanced eusocial species studied have been ants, most of the primitively eusocial species bees and most of the solitary species sawflies, it is difficult to attribute any apparent differences in these heterozygosities to sociality or other behavioural/ecological factors correlated with taxonomic grouping, or indeed, to the laboratory conducting the study (Selander, 1976; Simon and Archie, 1985).

Our estimate of heterozygosity for $A$. striata indicates a much greater degree of genetic variation in this species in comparison to other bees studied to date. This high level of allozyme variation is unlikely to be an artefact of the sample of enzyme systems for two reasons. First, most surveys of insect allozyme variation have considered fewer than half the number of loci included in our study. Furthermore, it is generally found that as more loci are taken into consideration the measured 
heterozygosity drops rather than rises (Nei and Roychoudhury, 1982; Singh and Rhomberg, 1987). Secondly, using an almost identical list of enzymes, we have reported a heterozygosity of only 0.038 $( \pm 0.003)$ for another bee species, a value typical for Hymenoptera (Packer and Owen, 1989) and similarly low levels for a range of other members of the bee family Halictidae (Packer and Owen, in preparation). Consequently, we believe our estimate to be an accurate reflection of a high level of genetic variation in this population. But why is this population so variable in comparison to other bees?

Low levels of genetic variation in the Hymenoptera have been explained in terms of (i) the ameliorating effects of the nest environment, (ii) low effective population sizes due to sociality in some species, (iii) low effective population sizes due to haplodiploidy, (iv) the removal of even slightly deleterious mutations via the hemizygous males and (v) the greater difficulty in obtaining a balanced polymorphism in haplodiploid (or sex linked) genetic systems. The last three explanations have haplodiploidy as their underlying cause and, as $A$. striata is also haplodiploid, release from these constraints is an unlikely explanation of the high level of genetic variation in this population. The first two hypotheses are variations of the more generally applicable explanations for high levels of genetic variation: large population size and spatiotemporal heterogeneity (Nevo et al., 1984).

The very primitive nature of the social organisation of $A$. striata means that the small effective population size that advanced eusociality may confer is inoperative in this case. However, this species, like most ground-nesting bees and wasps, may be expected to have a demography typified by frequent population bottlenecks. This is because the low successional stage habitats required by these species are inherently unstable and even when large aggregations build up they may be extirpated as a result of increases in predator and parasite populations (Knerer, 1973). The population under consideration was estimated to consist of around 1000 nests and is unlikely to have persisted for more than twenty years (Packer et al., $1989 b$ ). Large effective population size is unlikely to be a cause of the high level of genetic variation in this marginal, isolated population.

The low degree of social evolution and simple nest architecture of this species are unlikely to confer any environmental amelioration unlike the situation in some of the advanced eusocial ants and bees. Indeed, it is possible that this population experiences large fluctuations in environmental conditions-particularly temperature and humidity, when in the nest. This is because the bees nested in small patches of earth amongst stones and rocks directly exposed to incident sunlight. The temperatures and humidities experienced by developing immatures and adults within nests fluctuated markedly (Packer et al., 1989a). Further research is required to test whether this high level of genetic variation is promoted by extremes in environmental variation experienced by the bees. Detailed examples of adaptive polymorphisms at single loci in insects are reviewed by Zera et al. (1983).

The finding of highly significant linkage disequilibrium, even between only two of the loci, is interesting because values of D for allozyme loci are typically close to zero in outbred populations unless the loci are tightly linked (Hedrick, 1985). Also, as far as we are aware, this is the first reported case of linkage disequilibrium in the Hymenoptera. Although we made 21 pair-wise comparisons to detect linkage disequilibrium, the high significance level obtained between observed and expected genotypes for Dia-2 and Lap suggests that type 1 statistical error is unlikely to have produced this result.

Gametic frequency disequilibrium can arise from a number of different, although not necessarily mutually exclusive, causes include gene flow, genetic drift, hitch-hiking and (direct) selection (Hedrick, 1985). Here we examine two of these possibilities which may be relevant to the biology of $A$. striata. It should be noted that since no significant disequilibrium was observed between the other pairs of loci the following deductions require that they all be unlinked or effectively so with $c_{\mathrm{f}}$ values of $0 \cdot 5$, otherwise they too would be in disequilibrium.

Disequilibrium between two selectively neutral genes can be generated by genetic drift. In this case, the expected square of the correlation coefficient is related to the effective population size $N_{\mathrm{e}}$ and the recombination rate $c$ by the formula

$$
E\left(r^{2}\right) \approx 1 /\left(1+4 N_{\mathrm{e}} c\right)
$$

as given by Hill and Robertson (1968). Substituting in the observed value of $0 \cdot 12$ for $E\left(r^{2}\right)$ gives $N_{\mathrm{e}} c=$ $1 \cdot 762$. At haplodiploid loci there is no recombination in males so that $c=0 \cdot 5 c_{\mathrm{f}}$, where $c_{\mathrm{f}}$ is the recombination rate in females, thus $N_{\mathrm{e}} c_{\mathrm{f}}=3 \cdot 524$. Therefore, the possible $N_{\mathrm{e}}$ values that could generate the observed amount of disequilibrium range from 3524 to 7 for biologically realistic values of $c_{\mathrm{f}}$ between 0.001 and 0.5 (table 5 ). Hence, if these loci are reasonably tightly linked with $c_{\mathrm{f}}$ on the 
Table 5 Estimates of effective population size and selection coefficient provided by varying the recombination rate between the two loci Dia-2 and Lap for the two models discussed in the text. Each value of $c$ is given with the corresponding value of $N_{\mathrm{e}}$ or $s$ which would account for the observed linkage disequilibrium under either drift or selection respectively

\begin{tabular}{lcccccl}
\hline$c$ & 0.001 & 0.005 & 0.01 & 0.05 & 0.1 & 0.5 \\
$N_{\mathrm{e}}$ & 3524 & 705 & 352 & 70 & 35 & 7 \\
$s$ & 0.002 & 0.010 & 0.021 & 0.103 & 0.206 & 1.03 \\
\hline
\end{tabular}

order of $0 \cdot 01$, then an intermediate effective population size of about 350 could account for the observed disequilibrium, which would be expected to decay slowly over time. The values for $N_{\mathrm{e}}$ suggested in table 5 are in reasonable agreement with the range of population sizes expected for this population.

Alternatively, selection could generate disequilibrium in a number of different ways. If one or both of the allozyme loci are linked to a third, unknown locus undergoing selection, then although they may be selectively neutral themselves, disequilibrium can occur for some generations through the hitch-hiking effect (Thomson, 1977). If the allozyme loci are directly selected, then using the results of Hastings (1981), we can place limits on the strength of selection required to produce the observed disequilibrium. From figure 1 of Hastings (1981), we obtain an approximate value of 1.028 for the ratio of the recombination rate to the selection coefficient $s$ which would cause the observed disequilibrium. Because $c=$ $0 \cdot 5 c_{\mathrm{f}}$, the ratio $c_{\mathrm{f}} / s=2 \cdot 056$, which for various values of $c_{\mathrm{f}}$ gives the corresponding values of $s$ as shown in table 5. Therefore, unless the loci are very tightly linked, unreasonably strong selection on the gene combinations is required to maintain the observed disequilibrium.

Clearly, it is not possible on the basis of our knowledge, to reject either drift or selection as the cause of the observed disequilibrium. Nonetheless, selection has been implicated in the generation of linkage disequilibrium between allozyme loci in natural populations in other organisms. SmitMcBride et al. (1988) found significant linkage disequilibrium in 16.7 per cent of pairwise comparisons between four reasonably closely linked allozyme loci in Drosophila melanogaster. They considered the effective population sizes required to generate these disequilibria to be unrealistic. Moreover, linkage disequilibrium between some of the same pairs of loci was also observed in their controlled, experimental populations. They con- cluded that natural selection was the most likely cause of the disequilibrium.

In principle, linkage disequilibrium is easy to detect in Hymenoptera because of male haploidy. We hope that other workers will be stimulated to collect the appropriate data when undertaking electrophoretic surveys.

Diploid males are expected to occur in reasonably large, outbred populations because the alleles at the sex-determining locus (or loci) are maintained through a balance between mutation, drift and selection (Yokoyama and Nei, 1979).

Diploid males, although commonly produced by inbreeding (Crozier, 1977), have been recorded in a few natural populations of Hymenoptera, including the halictine bee Lasioglossum zephyrum (Kukuk, 1989). Kukuk found diploid males at frequencies of 0.14 and 0.02 at two nest aggregations of $L$. zephyrum in the northeastern U.S.A. Our value for $\boldsymbol{A}$. striata falls within this range and implies an outbred population with a reasonably large number of sex determining alleles segregating.

If we assume single locus sex determination, then we can estimate effective population size using the theory developed by Yokoyama and $\mathrm{Nei}$ (1979). The proportion of diploid males, $\phi$, is the same as the expected homozygosity at the sex determination locus-Yokoyama and Nei's J. From table 1 of Yokoyama and $\mathrm{Nei}$, we see that our value of $\phi \equiv \mathrm{J}$ corresponds to an $N_{\mathrm{e}}$ of approximately 5000. A smaller $N_{\mathrm{e}}$ would lead to a higher proportion of diploid males. For example, an $N_{\mathrm{e}}$ of 2000 would give a $\phi$ of 0.05 , the upper limit $(\phi+$ S.E. $)$ estimated from our sample.

Acknowledgements We thank the Natural Sciences and Engineering Research Council of Canada for their financial support of the research reported here. Funding for the specimen collection phase of this research was provided by the University College of Cape Breton. We thank Colleen Renchko for technical assistance.

\section{REFERENCES}

AYAla, F. J., POWELl, J. R., TRACEY, M. L., MOURAO, C. A. AND PEREZ-SALAS, S. 1972. Enzyme variability in the Drosophila willistoni group. IV. Genic variation in natural populations of Drosophila willistoni. Genetics, 70, 113-139. BERKELHAMER, R. C. 1983. Intraspecific genetic variation and haplodiploidy, eusociality, and polygyny in the Hymenoptera. Evolution, 37, 540-545.

BREWER, G. W. 1970. An introduction to isozyme techniques. Academic Press, New York. 
CARDY, B. J. STUBER, C. W. AND GOODMAN, M. M. 1980. Techniques for starch gel electrophoresis of enzymes from maize (Zea mays L.). Inst. of Statistics Mim. Ser. No. 1317. North Carolina State University, Raleigh, N.C.

CLAYTON, J. W. AND TRETIAK, D. N. 1972. Amine-citrate buffers for $\mathrm{pH}$ control in starch gel electrophoresis. J. Fish Res. Bd. Canada, 29, 1169-1172.

CROZIER, R. C. 1970 . On the potential for genetic variability in haplo-diploidy. Genetica, 41, 551 556.

CROZIER, R. C. 1977. Evolutionary genetics of the Hymenoptera. Ann. Rev. Entomol. 22, 263-268.

GRAUR, D. 1985. Gene diversity in Hymenoptera. Evolution, 39, 190-199.

HALDANE, J. B. S. 1926. A mathematical theory of natural and artificial selection. Part III. Proc. Camb. Phil. Soc., 23, $363-372$.

HAMILTON, W. D. The genetical evolution of social behaviour. I and II. J. Theor. Biol., 7, 1-52.

HARRIS, H. AND HOPKINSON, D. A. 1976. Handbook of Enzyme Electrophoresis in Human Genetics. Elsevier, New York.

HASTINGS, A. 1981. Disequilibrium, selection, and recombination: limits in two-locus, two-allele models. Genetics, 98, 659-668.

HEDRICK, P. W. 1985. Genetics of Populations. Jones and Bartlett Inc., Boston.

HILL, W. G. 1974. Estimation of linkage disequilibrium in randomly mating populations. Heredity, 33, 229-239.

HILL, W. G. AND ROBERTSON, A. 1968. Linkage disequilibrium in finite populations. Theor. Appl. Genet., 38, 226-231.

KNERER, G. 1973. Periodizitat und Strategie der Schmarotzer einer socialen Schmalbiene, Evylaeus malachurus (K.). Zool. Anz. 190, 41-63.

KUENZI, F. M. AND COPPEL, H. C. 1986. Isozymes of the sawflies Neodiprion and Diprion similis: diagnostic characters and genetic distance. Biochem. Syst. Ecol., 14, 423-429.

KUKUK, P. F. AND MAY, B. 1985. A re-examination of genetic variability in Dialictus zephyrus (Hymenoptera: Halictidae). Evolution, 39, 226-228.

KUKUK, P. 1989. Evolutionary genetics of a primitively eusocial halictine bee, Dialictus zephyrus. pp. 183-202. In Breed, M. D. and Page, R. E. (eds.) The Genetics of Social Evolution, Westview Press, Boulder CO.

MANDEL, S. P. H. 1959. Stable equilibrium at a sex-linked locus. Nature, 183, 1347-1348.

METCALF, R. A. MARLIN, J. C. AND WHITT, G. S. 1975. Low levels of genetic heterozygosity in Hymenoptera. Nature, 257, 792-794.

METCALF, R. A. MARLIN, J. C. AND WHITT, G. S. 1984. Genetics of speciation within the Polistes fuscatus species complex. J. Hered., 75, 117-120.

MICHENER, C. D. 1974. The Social Behavior of the Bees. Belknap. Harvard.

NEI, M. AND ROYCHOUDHURY, A. K. 1974. Sampling variances of heterozygosity and genetic distance. Genetics, 76, 379 390.

NEVO, E., BEILES, A. AND BEN-SHLOMO, R. 1984. The evolutionary significance of genetic diversity: ecological, demographic and life history correlates. Lecture Notes in Biomathematics, 53, 13-213.

OWEN, R. E. 1985. Difficulties with the interpretation of patterns of genetir ariation in the eusocial Hymenoptera. Evolution, 39, 201-205.

OWEN, R. E, 1988. Selection at two sex-linked loci. Heredity, $60,415-425$.
PACKER, L., JESSOME, V., LOCKERBIE, C. AND SAMPSON, B. $1989 a$. The phenology and social biology of four sweat bees in a marginal environment: Cape Breton Island. Can. J. Zool., 67, 2871-2877.

PACKER, L. AND OWEN, R. E. 1989. Allozyme variation in Halictus rubicundus: a primitively social bee (Hymenoptera; Halictidae). Can. Entomol., 121, 1049-1058.

PACKER, L., SAMPSON, B., LOCKERBIE, C. AND JESSOME, V. $1989 \mathrm{~b}$. Nest architecture and brood mortality in some sweat bees (Hymenoptera; Halictidae) from Cape Breton Island. Can. J. Zool., 67, 2864-2870.

PAMILO, P. AND CROZIER, R. C. 1981. Genic variation in male haploids under deterministic selection. Genetics, 98, 199214

PAMILO, P., VARVIO-AHO, S.-L., AND PEKKARINEN, A. 1978 Low enzyme gene variability in Hymenoptera as a consequence of haplodiploidy. Hereditas, 88, 93-99.

RIDGWAY, G. J., SHERBURNE, S. L. AND LEWIS, R. D. 1970. Polymorphism in the esterases of atlantic herring. Trans. Amer. Fish. Soc., 99, 147-151.

SELANDER, R. K. 1976. Genetic variation in natural populations. pp. 21-45. In Ayala, F. J. (ed.) Molecular Evolution, Sinauer, Sunderland MA.

SELANDER, R. K. AND KAUFMAN, D. W. 1973. Genic variability and strategies of adaptation in animals. Proc. Natl Acad. Sci. USA, 70, 1875-1877.

SHAW, C. R. AND PRASAD, R. 1970. Starch gel electrophoresis of enzymes-a compilation of recipes. Biochem. Gen, 4, 291-320.

SIMON, C. AND ARCHIE, J. 1985. An empirical demonstration of the lability of heterozygosity estimates. Evolution, 39, 463-467.

SINGH, R. S. AND RHOMBERG, L. R. 1987. A comprehensive study of genic variation in natural populations of Drosophila melanogaster. II. Estimates of heterozygosity and patterns of geographic differentiation. Genetics, 117, 255-271.

SMIT-MCBRIDE, Z., MOYA, A. AND AYALA, F. J. 1988. Linkage disequilibrium in natural and experimental populations of Drosophila melanogaster. Genetics, 120, 1043-1051.

SNYDER, T. P. 1974. Lack of allozyme variability in three bee species. Evolution, 28, 687-698.

SOKAL, R. R. AND ROHLF, F. J. 1981. Biometry. Freeman, New York.

SUOMALAINEN, E. 1962. Significance of parthenogenesis on the evolution of insects. Ann. Rev. Entomol., 7, 349-366.

THOMSON, G. 1977. The effect of a selected locus on linked neutral loci. Genetics, 85, 753-788.

WADE, M. J. AND BREDEN, F. 1981. Effect of inbreeding on the evolution of altruistic behavior by kin selection. Evolution, $35,844-858$.

WOODS, P. E. AND GUTTMAN, S. L. 1987. Genetic variation in Neodiprion (Hymenoptera: Symphyta: Diprionidae) Sawflies and a comment on low levels of genetic diversity within the Hymenoptera. Ann. Entomol. Soc. Amer., 80, 590-599.

YOKOYAMA, S. AND NEI, M. 1979. Population dynamics of sex-determining alleles in honey bees and self-incompatibility alleles in plants. Genetics, 91, 609-626.

ZAR, J. H. 1984. Biostatistical Analysis, 2nd edn. Prentice-Hall, Englewood Cliffs, N.J.

ZERA, A. J. KOEHN, R. K. AND HALL, J. G. 1983. Allozymes and biochemical adaptation. pp. 633-674. In Kerkut, G. A. and Gilbert, L. I. (eds) Comprehensive Insect Physiology, Biochemistry and Pharmacology, Vol. 10, Gilbert. Pergamon, U.K. 